\title{
Innervation of Subclavius Muscle: An Anatomical Study
}

\author{
Inervación del Músculo Subclavio: Un Estudio Anatómico
}

\author{
Anna Jeon ${ }^{1}$; Chang Min Seo ${ }^{1}$; Young Joon Choi²; Je-Hun Lee ${ }^{3 *}$ \& Seung- Ho Han ${ }^{\text {* }}$
}

JEON, A.; SEO, C. M.; CHOI, Y. J.; LEE, J. H. \& HAN, S. H. Innervation of subclavius muscle: An anatomical study. Int. J. Morphol., 36(3):817-820, 2018.

SUMMARY: This study was aimed to provide accurate parameters to localize the nerve endings for subclavius muscle belly and to investigate the basic information on nerve innervations on subclavius muscle. Twenty-two adult non-embalmed cadavers ( 7 males and 4 females) with a mean age of 68.7 years (range, $43-88$ years) were enrolled for the present study. For measurements, the most prominent point of the sternal end of the clavicle (SEC) on anterior view and the most prominent point of the acromial end of the clavicle (AEC) were identified as the reference point. A line connecting the SEC and AEC was used as a reference line. Among all the measured points, $92.2 \%$ of the points were gathered from 40 to 60 distances on the reference line. In one male specimen, both the sides of the nerve to the subclavius were merged with the phrenic nerve. It is further hypothesized that the basic anatomical results about the nerve branching pattern will be helpful in the clinical field.

KEY WORDS: Subclavius; Thoracic outlet syndrome; Anatomical study; Innervation.

\section{INTRODUCTION}

The thoracic outlet syndrome (TOS) includes a condition of upper limb disorders, which is considered to occur due to isolated or combined compression of neurovascular structures in the shoulder region (Torriani $e t$ al., 2010). The scalene muscles generally are known as pectoralis minor or subclavius muscle can cause upper limb pain (Torriani et al.).

A specific research emphasized that one of the causes of TOS is the shape of subclavius. The subclavius posticus muscle (SPM) is an aberrant muscle originating from the medial aspect of the first rib reaching to the superior margin of the scapula, which may cause, depending on its activation, dynamic compression of the brachial plexus. In case of patients with TOS, possibilities exist for the development of carpal tunnel syndrome (Muellner et al., 2015).

Several treatment procedures for TOS such as anesthetic and botulinum toxin injections, physical therapy or surgical intervention are popular, and the botulinum toxin injection has been reported to exhibit maximal effect by spreading in the region nearest to the nerve point in the muscle belly (Childers et al., 1998). A study on botulinum toxin injection demonstrated good outcome, however, it was done with ultrasound-guided approach (Torriani et al.). When the surgeon injected without medical instruments, it is not easy to inject exactly in the point where they want.

Only few animal studies have reported about nerve innervations of the subclavius (Sterba, 1967; Tanaka et al., 1988). There hardly exists any anatomical study based on human target on subclavius muscle innervations pattern. Only one study had reported the innervated information that accessory phrenic nerve contains a C5 segment; however, not much data was provided on the subclavius muscle with innervations information (Banneheka, 2008).

Therefore, in this study, we aimed to provide accurate parameters to localize the nerve endings for subclavius muscle belly and to investigate the basic information on nerve innervations on subclavius muscle.

${ }^{1}$ Department of Anatomy, College of Medicine, Chung-Ang University, Seoul, Korea.

${ }^{2}$ Department of Gynecology, KyungHee University Hospital, Seoul, Korea.

${ }^{3}$ Anatomy laboratory, College of Sports Science, Korea National Sport University, Seoul, Korea.

"These authors contributed equally to this work.

Grant sponsor. This work was supported by the National Research Foundation of Korea (NRF) grant funded by the Korea government $\left(\right.$ MSIT) $\left(\mathrm{N}^{\circ}\right.$ 2016R1A1A1A05005480). This research was supported by the Chung-Ang University Research Scholarship Grants in 2016. 


\section{MATERIAL AND METHOD}

Twenty-two adult non-embalmed cadavers ( 7 males and 4 females) with a mean age of 68.7 years (range, $43-88$ years) were enrolled for the present study. The specimens were chosen without a history of clavicle fracture or prior surgery on the clavicle or shoulder.

With the specimen in the supine position, different colored latexes were injected into the artery (pink) and vein (blue) on the elbow to the shoulder region. Only the skin with superficial fascia was removed to expose the muscle of the surrounding region of subclavius. The pectoralis major under the clavicle region was carefully removed and the medial part of the clavicle was carefully removed without damaging the subclavius. Subsequently, we tried to find nerve branch from the cervical plexus traveling to the subclavius (Fig. 1).

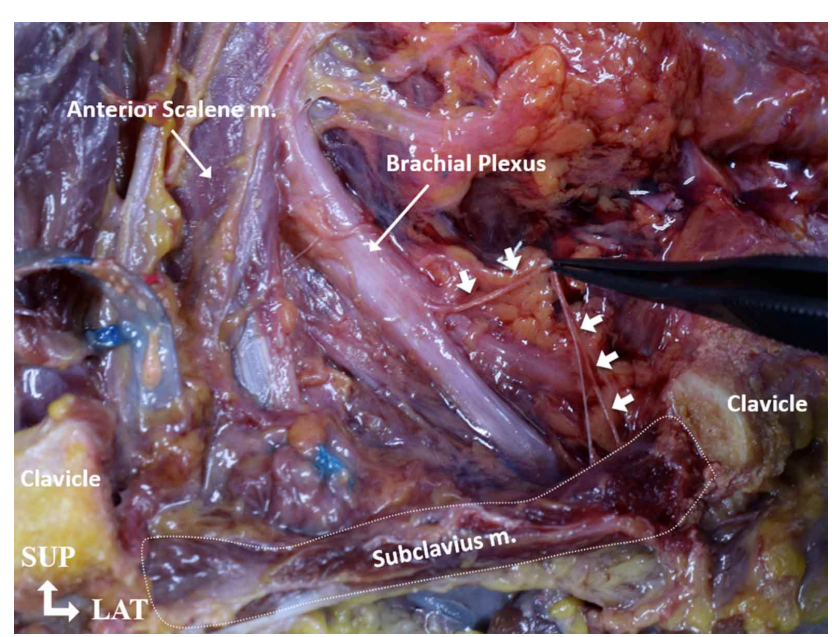

Fig. 1. Left clavicular region showing distribution pattern of vessels after injection of latex with different colors. Dotted line, subclavius; arrowed head, nerve entering into the subclavius; SUP, superior; MED, medial.
In this study two variables were measured, branching out point from the brachial plexus and nerve entering point into the subclavius belly. Also, we counted the number of nerve branches. For measurements, the most prominent point of the sternal end of the clavicle (SEC) on anterior view and the most prominent point of the acromial end of the clavicle (AEC) were identified as the reference point. A line connecting the SEC and AEC was used as a reference line. The $\mathrm{x}-$ coordinate was expressed in the absolute distance along the reference line using the SEC as the starting point. The ycoordinate was expressed in absolute distance perpendicular to the reference line. The locations of the nerve branches are presented with respect to the reference line (Fig. 2).

A single observer carried out all the measurements using a measuring tape and digital calipers (resolution $0.01 \mathrm{~mm}, \mathrm{CD}-$ 20PSX, Mitutoyo, Japan). Data were analyzed using SPSS software version 23.0 (IBM SPSS Inc., Chicago, IL, USA).

\section{RESULTS}

The mean distance of the reference line from the SEC to AEC was $16.3 \pm 1.4 \mathrm{~cm}$. There was no significant difference in reference line distance between males and females or between right and left sides ( $p \geq 0.05$ ).

The number of nerve branches entering into the muscle belly was $25.0 \%$ for $1,55 \%$ for 2 and $20 \%$ for 3 branches (Table I).

The branching out the point of brachial plexus was located at $6.7 \%$ on the x-coordinate, $3.2 \%$ on the y-coordinate of the reference line from the SEC, respectively (Fig. 1). In one male specimen, both sides of the nerve to the subclavius were merged with the phrenic nerve (Fig. 3). Among all the measured points, $92.2 \%$ of the points were gathered from 40 to 60 distances on the reference line (Table II) (Fig. 4).
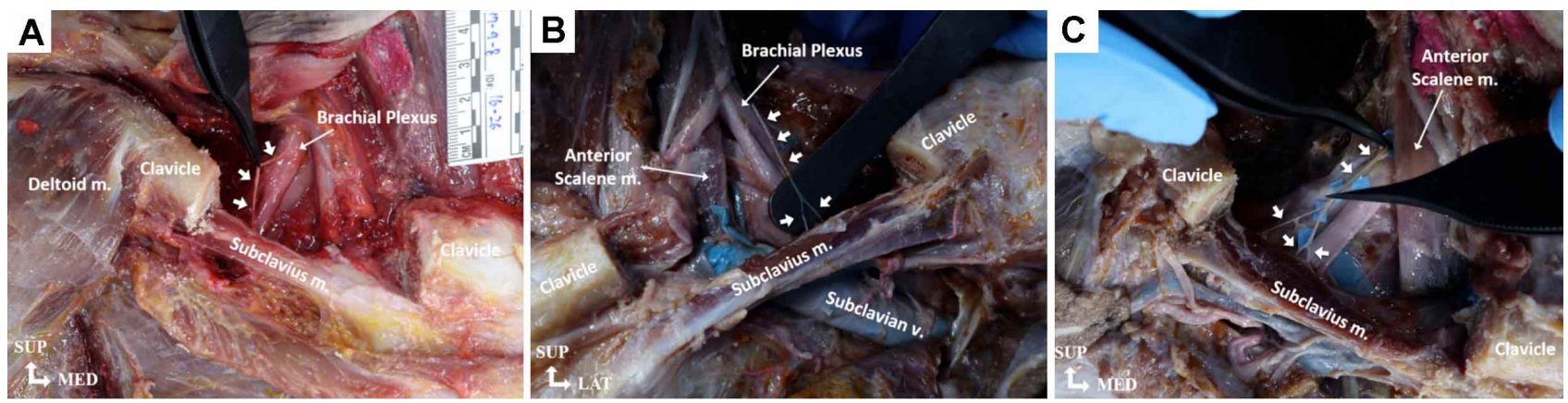

Fig. 2. Nerve branching pattern entering into the subclavius and removal of the middle of the clavicle. A; 1 nerve branch, B; 2 nerve branches, C; 3 nerve branches. Arrowed head, nerve entering into the subclavius; SUP, superior; MED: medial; LAT, lateral. 


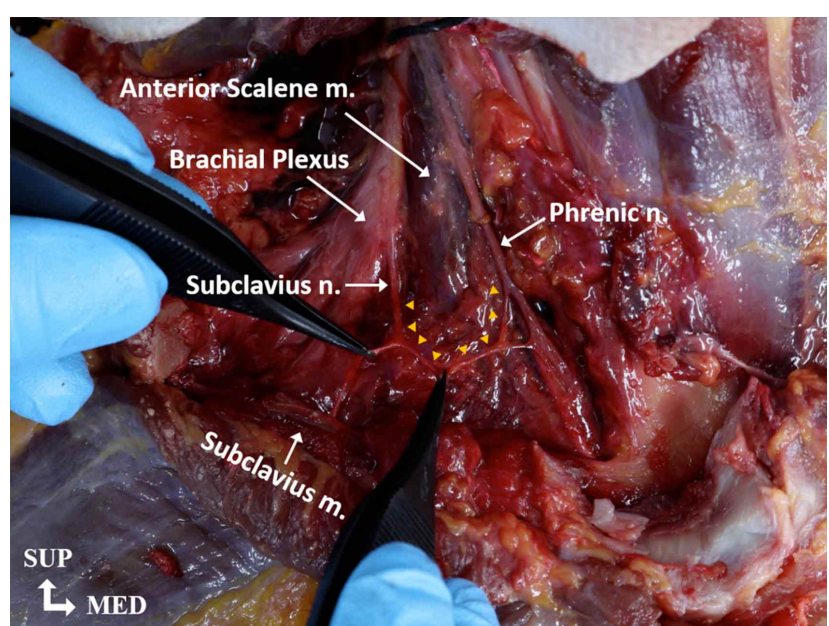

Fig. 3. Nerve entering into the subclavius connected with the phrenic nerve. Yellow arrowhead, connected nerve arch; SUP, superior; LAT, lateral; ANT, anterior.
Table I. The number of nerve branches entering the subclavius muscle belly in this study.

\begin{tabular}{ccc}
\hline $\begin{array}{c}\text { Number of nerve } \\
\text { branches }\end{array}$ & $\begin{array}{c}\text { Number of } \\
\text { specimens }\end{array}$ & $\%$ \\
\hline 1 & 5 & 25.0 \\
2 & 11 & 55.0 \\
3 & 4 & 20.0 \\
\hline
\end{tabular}

Table II. The distribution frequency of the nerve entering into the muscle belly on the reference line.

\begin{tabular}{ccccc}
\hline $\begin{array}{l}\text { Section on the } \\
\text { reference line }\end{array}$ & $20-30$ & $30-40$ & $40-50$ & $50-60$ \\
\hline Number $(\%)$ & $1(2.6)$ & $1(2.6)$ & $19(48.7)$ & $18(46.1)$ \\
\hline
\end{tabular}

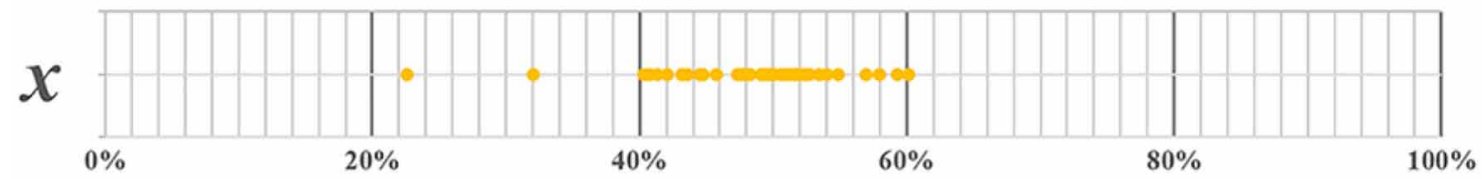

Fig. 4. Degree of nerve distribution to enter the subclavius muscle belly on the reference line. X, x-coordinate on the reference line

\section{DISCUSSION}

Thoracic outlet syndrome usually targets the structures near the clavicle. In case of surrounding muscles near the clavicle, the presence of neurovascular structures like a transverse cervical artery, the internal or external jugular veins, and thoracoacromial trunk significantly limits the choice of potential needle site. The injection to the subclavius is relatively easier than other muscles, which are the cause of thoracic outlet syndrome. The recommended site for injection according to the reference line on the clavicle can provide valuable information about the clinical field.

An anatomical study by Banneheka identified the phrenic nerve and accessory phrenic nerve. In their study, most of the accessory phrenic nerve contained a C5 segment and the nerve to subclavius was the commonest source. The reported study did not distinguish between phrenic and accessory phrenic nerve, but in our study, we found a single case in which the nerve entering the subclavius muscle was combined with the phrenic nerve (Fig. 3). It is important to dissect the nerve branch and investigate the manner in which they get into a network with each other, and it is also clinically imperative to identify the site for the injection.
In textbooks, the subclavius is generally introduced as the name of the 'nerve to subclavius' and that the nerve to subclavius branches into the roots of C3-5 spinal nerves (Moore et al., 2002; Standring, 2005). On the other hand, Gray's textbook (Standring) describes that the origin of 'nerve to subclavius' is the superior trunk of the brachial plexus. In the present study, we found a case that was connected with phrenic nerve, and rest of them were isolated independently. The results reveal that 'nerve to subclavius' was branched from the brachial plexus with $6.7 \%$ on $x-$ coordinate and $3.2 \%$ on the y-coordinate. However, it is impossible to define that which main trunk branches out because the perineurium and a twist in each nerve were observed as limiting factors. We hypothesize that the results of the present study will contribute greatly towards basic anatomical knowledge.

In conclusion, the nerve branch to enter the muscle belly was densely distributed at the 3rd section (40-60 \%) on the injection target of the subclavius (Fig. 4). It is further hypothesized that the basic anatomical results about the nerve branching pattern will be helpful in the clinical field. 
JEON, A.; SEO, C. M.; CHOI, Y. J.; LEE, J. H. \& HAN, S. H. Inervación del Músculo Subclavio: Un Estudio Anatómico. Int. J. Morphol., 36(3):817-820, 2018.

RESUMEN: El objetivo de este estudio fue proporcionar parámetros precisos para localizar las terminaciones nerviosas correspondientes al músculo subclavio e investigar la información básica sobre la inervación de los nervios en el músculo subclavio. Fueron incluidos 22 cadáveres adultos no fijados (7 hombres y 4 mujeres) con una edad media de 68,7 años (rango: 43-88 años). Para las mediciones se identificaron como punto de referencia, el punto más prominente del extremo esternal de la clavícula (SEC) en la vista anterior y el punto más prominente de la parte acromial de la clavícula (AEC). Se utilizó una línea que conecta la SEC y AEC como línea de referencia. Entre todos los puntos medidos, el $92,2 \%$ de los puntos se obtuvieron de 40 a 60 distancias en la línea de referencia. En un espécimen masculino, a ambos lados, el nervio del músculo subclavio se presentó fusionado con el nervio frénico. Además, se plantea la hipótesis de que los resultados anatómicos básicos sobre el patrón de ramificación nerviosa serán útiles en el campo clínico.

PALABRAS CLAVE: Músculo subclavio; Síndrome del opérculo torácico; Estudio anatómico; Inervación.
Corresponding author:

Professor Je-Hun Lee

Anatomy Lab., College of Sports Science Korea

National Sport University

Seoul

REPUBLIC OF KOREA

Email: leejehun@knsu.ac.kr

Professor Seung-Ho Han

Department of Anatomy

Chung-Ang University

Seoul

REPUBLIC OF KOREA

Email: monami@cau.ac.kr

Received: $31-01-2018$

Accepted: 13-03-2018

\section{REFERENCES}

Banneheka, S. Morphological study of the ansa cervicalis and the phrenic nerve. Anat. Sci. Int., 83(1):31-44, 2008.

Childers, M. K.; Kornegay, J. N.; Aoki, R.; Otaviani, L.; Bogan, D. J. \& Petroski, G. Evaluating motor end-plate-targeted injections of botulinum toxin type A in a canine model. Muscle Nerve, 21(5):653-5, 1998.

Moore, K. L.; Agur, A. M. \& Dalley, A. F. Essential Clinical Anatomy. Philadelphia, Lippincott Williams \& Wilkins, 2002.

Muellner, J.; Kaelin-Lang, A.; Pfeiffer, O. \& El-Koussy, M. M. Neurogenic thoracic outlet syndrome due to subclavius posticus muscle with dynamic brachial plexus compression: a case report. B. M. C. Res. Notes, 8:351, 2015.

Standring, S. Gray's Anatomy. The Anatomical Basis Of Clinical Practice. $39^{\text {th }}$ ed. Edinburgh, Elsevier Churchill Livingstone, 2005.

Sterba, O. The homology of the m. subclavius in the horse (Equus caballus L.). Anat. Anz., 120(1):41-6, 1967.

Tanaka, S.; Zukeran, C. \& Nakagawa, S. A macroscopical study of the subclavius muscle of the rat. Anat. Anz., 165(5):417-24, 1988.

Torriani, M.; Gupta, R. \& Donahue, D. M. Botulinum toxin injection in neurogenic thoracic outlet syndrome: results and experience using a ultrasound-guided approach. Skeletal Radiol., 39(10):973-80, 2010. 